\title{
A SEPARAÇÃO DE PODERES E A CONSOLIDAÇÃO DA ORDEM DEMOCRÁTICA NO BRASIL ${ }^{*}$
}

\author{
Celso de Mello \\ Ministro, Presidente do Supremo Tribunal Federal
}

Mais do que o exercício ritual de uma celebração, esta solenidade, tãoimpregnada de expressivo significado histórico, representa um momento importante de confirmação de nossa fé em valores que jamais poderão ser desrespeitados ou esquecidos pelas inúmeras gerações, que, sucedendo-se no tempo, formam um elo contínuo capaz de construir, pela permanente renovação da esperança, o sonho alimentado pelos ideais de Justiça que pulsam, intensamente, no espírito daqueles que ainda conservam viva, em seus corações, a chama ardente dos anos de juventude acadêmica.

A Academia de Direito de São Paulo, em seu itinerário histórico, forjou-se como instrumento de concretização de nossa independência cultural e elemento de consolidação de nosso projeto político como Estado nacional soberano.

O espírito da Academia, que nos envolve a todos, confere-nos uma identidade comum, confirmada, a cada momento, pelos desafios, pelas crises, pelos dilemas e pelos anseios de gerações de estudantes, que, com dignidade e notável percepção das exigências éticas impostas pela consciência democrática, foram sempre capazes de opor-se, em instantes cruciais da vida política nacional, a estruturas autoritárias que buscavam monopolizar, com absoluta arrogância e avidez de poder, o controle do Estado e o domínio institucional da sociedade civil.

Os sonhos generosos, que tanto inspiraram os estudantes da Faculdade de Direito do Largo de São Francisco, em sua longa existência histórica iniciada em 11 de agosto de 1827, nada mais refletem senão a plenitude do espírito acadêmico, capaz de estimular, em cada um de nós, um insuprimível senso de responsabilidade cívica, animado por este poderoso sentimento interior de liberdade que nos impulsionou, sem desânimo, no esforço ingente de repudiar o progressivo aumento

\footnotetext{
* Palestra proferida em solenidade de encerramento das comemorações dos 170 anos de sua existência, na Faculdade de Direito da Universidade de São Paulo, em 15.08.1997.
} 
do coeficiente de tutela que vocações totalitárias impuseram ao povo deste País ao longo de nosso processo histórico.

Não há dúvida de que estas Arcadas que nasceram sob o signo da liberdade - representam, na experiência concreta de sua trajetória institucional, o testemunho fiel do compromisso histórico de seus Alunos e Professores com a causa da democracia.

O legado da Faculdade de Direito do Largo de São Francisco, transmitido, continuamente, de geração a geração, a todos os que transpuseram os seus umbrais, é imenso e é indestrutível, pois marcou-nos com lição que ainda pulsa em nossos corações, ensinando-nos que o respeito à ordem constitucional, legitima a repulsa ao arbítrio e a proteção das liberdades qualificam-se como fins superiores que devem inspirar a conduta daqueles que pretendem construir, edificar e consolidar, no Brasil, o Estado democrático de Direito.

Dentro desse contexto, é preciso enfatizar que o Supremo Tribunal Federal e esta Academia sempre mantiveram íntima vinculação, revelada por fortes laços que unem, historicamente, aquele órgão de cúpula da Justiça brasileira à Faculdade de Direito do Largo de São Francisco, que, ao longo do período republicano, foi responsável pela formação acadêmica de mais de $1 / 3$ dos magistrados que compuseram a Corte Suprema do Brasil.

Cabe mencionar, por oportuno, que, na instalação do Supremo Tribunal Federal, ocorrida a 28 de fevereiro de 1891, na cidade do Rio de Janeiro, seis (6) de seus primeiros quinze (15) Juízes procediam da Faculdade de Direito do Largo de São Francisco: João Evangelista Negreiros Saião Lobato, Visconde de Sabará (1836); Ovídio Fernandes Trigo de Loureiro (1848); Olegário Herculano D'Aquino e Castro (1848); Tristão de Alencar Araripe (1845); João José de Andrade Pinto (1846); Joaquim Francisco de Faria (1850) e Joaquim de Toledo Piza e Almeida (1866).

Grandes vultos do Supremo Tribunal Federal, magistrados eminentes da Suprema Corte brasileira, passaram pelos bancos acadêmicos da Faculdade de Direito do Largo de São Francisco, aqui graduando-se e aqui obtendo sólida formação jurídica. Outros, embora não houvessem cursado esta Academia de Direito, nela vieram a lecionar, tornando-se Mestres de inúmeras gerações estudantis.

Eis alguns desses nomes, que tanto dignificaram o Supremo Tribunal Federal e que muito honraram a Faculdade de Direito do Largo do São Francisco: 
- Américo Brasiliense de Almeida e Melo (aluno e professor)

- João Mendes de Almeida Júnior (aluno e professor)

- Pedro Lessa (aluno e professor)

Herculano de Freitas (aluno e professor)

Joaquim de Toledo Piza e Almeida (aluno e professor)

Alfredo Buzaid (aluno e professor)

José Linhares (aluno)

Canuto José Saraiva (aluno)

- Edmundo Muniz Barreto (aluno)

- Enéas Galvão (aluno), que, ao lado de Pedro Lessa, foi o grande formulador, como Juiz de nossa Suprema Corte, da doutrina brasileira do habeas corpus

Edmundo Lins (aluno)

Mário Guimarães (aluno)

Cândido Mota Filho (aluno e professor), também membro da Academia Brasileira de Letras (ABL)

João Luiz Alves (aluno), que também pertenceu à $\mathrm{ABL}$

José Geraldo Rodrigues de Alckmin (aluno)

Firmino Whitaker (aluno)

- Rodrigo Otávio (aluno), um dos fundadores, em 1897, da ABL

- Carvalho Mourão (aluno)

- Plínio Casado (aluno), que colou grau perante o Barão de Ramalho, grande Diretor da Faculdade de Direito de São Paulo

- Laudo de Camargo (aluno)

- Manoel da Costa Manso (aluno)

Ataulfo de Paiva (aluno), também membro da ABL

Américo Lobo (aluno)

Ubaldino do Amaral (aluno)

Pedro Chaves (aluno)

Hermes Lima (professor)

Raphael de Barros Monteiro (aluno)

Moacyr do Amaral Santos (aluno e professor)

José Carlos Moreira Alves (professor)

- Sydney Sanches (aluno). 
As sucessivas gerações acadêmicas que passaram pela Faculdade de Direito do Largo de São Francisco, inspiradas pela superioridade ético-política da ordem democrática e impulsionadas pela busca incessante das liberdades, sempre tiveram nítida consciência e clara percepção de que o respeito aos limites impostos pela Constituição atua como decisivo fator de equilíbrio das relações institucionais entre os Poderes do Estado.

Sabemos todos que a atividade inconstitucional do Poder Público projeta-se, anomalamente, como elemento de ruptura da harmonia que deve necessariamente pautar as ações desenvolvidas pelos Poderes da República.

O princípio da separação de poderes, além de qualificar-se como núcleo temático irreformável do ordenamento constitucional positivo brasileiro, reflete, na concreção do seu alcance, um significativo dogma de preservação do equilíbrio de nosso sistema político e de intangibilidade do modelo normativo das liberdades públicas, impedindo - a partir da estrita subordinação estatal aos limites impostos ao âmbito de atuação dos poderes constituídos que o regime democrático venha a ser conspurcado pelo exercício ilegítimo das prerrogativas estatais.

Torna-se necessário enfatizar e enfatizar com veemência, sempre que o coeficiente de liberdade dos Povos expõe-se a sensível e perigosa redução, quando os Poderes do Estado, ao usurparem atribuições institucionais que lhes não são próprias, transgridem o postulado da separação constitucional, dando indevida expansão às suas prerrogativas políticas e jurídicas, e, com esse comportamento revestido de ilicitude constitucional, vêm a desrespeitar a Constituição e a lesar, de maneira inaceitável, as liberdades civis e as franquias democráticas.

Processos de contínua usurpação de poderes e de competências constitucionais culminam por gerar, no âmbito da comunidade estatal, situações instauradoras de desrespeito sistemático do Poder Público ao regime essencial das liberdades públicas.

É preciso advertir, neste ponto, que as liberdades da pessoa, muitas vezes, expõem-se a um processo de quase imperceptível erosão, destruindo-se, lenta e progressivamente, pela ação usurpadora e insidiosa dos poderes estatais, que nem sempre agem, de maneira ostensiva, na busca autoritária de maior domínio sobre os direitos e garantias do cidadão.

Quando os Cursos Jurídicos foram instituídos em São Paulo e Olinda pela Lei de 11.08.1827, vigorava, já há quase três anos e meio, a Carta Política do Império do Brasil, cujo art. $9^{\circ}$ refletindo o verdadeiro significado finalístico que 
ainda hoje anima e orienta o princípio da divisão funcional do poder, proclamava que "a divisão e harmonia dos Poderes Políticos é o princípio conservador dos direitos dos cidadãos e o mais seguro meio de fazer efetivas as garantias que a Constituição oferece"

José Antônio Pimenta Bueno, Marquês de São Vicente, paulista eminente, graduou-se em Direito na primeira turma da Academia de São Paulo, em 1832. Foi ele, segundo consenso geral, o grande constitucionalista do Império, responsável pelo estabelecimento das bases do direito público imperial. Ao comentar o sentido e a razão de ser do princípio da separação de poderes consagrado pela Carta Política de 1824, Pimenta Bueno ("Direito Público Brasileiro e Análise da Constituição do Império" pp. 31/33, itens 26/28, 1958. Ministério da Justiça, Rio de Janeiro) deixou registrada esta lição impregnada de inquestionável atualidade:

"Quando se reflete sobre o fundo do preceito, sobre a força das expressões deste artigo constitucional, não é possivel deixar de admirar a extensão de suas vistas, a alta compreensão e o vigor de sua sabedoria!

$\mathrm{Na}$ infância das sociedades, ou antes da sua civilização, os Poderes Políticos em vez de divididos são confundidos e concentrados em uma mesma individualidade, e conseqüentemente entregues ao impulso, e por ventura desvarios de uma só vontade, por isso mesmo que em tal caso ela é ilimitada, absoluta, competente.

Os males que dai resultam são patentes e terríveis em suas conseqüências; a sociedade em todas as suas relações pende do arbítrio.

Pelo que respeita a garantias individuais é óbvio que nem uma existe, e nem pode existir contra a vontade ou contra o abuso de uma onipotência, que por seu próprio excesso torna-se irracional; aniquila-se toda a possibilidade de limites, de equilíbrio, de fiscalização, ou contenção política. Não podendo desde então haver governo livre não pode haver também liberdades públicas nem individuais; o homem é escravo, os seus caracteres morais $e$ intelectuais são degradados ou comprimidos. A única garantia eventual ou precária é a da virtude pessoal do governante quando bem informada. 
Em relação à administração pública, a sociedade necessariamente sofre, todos os interesses se ressentem. Não prevalecem os talentos, as luzes, as virtudes em seu impulso, sim as afeições pessoais, a desteridade dos válidos. Os interesses e relações sociais de ordens diversas, que a razão demanda que sejam confiados a poderes e pessoas distintas, que pressupõe habilitações e condições especiais, são confundidos, olvidados ou sacrificados; é o patrimônio pessoal maldirigido e defraudado.

Assim essa forma viciosa exerce nociva influência sobre os homens e sobre as cousas, sobre todas as relações da inteligência e vida dos individuos e do Estado.

Dai se manifesta claramente a necessidade essencial da divisão do poder, necessidade que uma civilização adulta trata logo de satisfazer. Essa divisão é quem verdadeiramente distingue e classifica as diversas formas dos governos, quem estrema os que são absolutos dos que são livres, quem enfim opera a distinção real dos diferentes interesses e serviços da sociedade. Sem ela o despotismo necessariamente deverá prevalecer, pois que para o poder não abusar é preciso que o poder contenha o poder.

Entretanto, para que a divisão dos poderes ministre seus beneficios resultados, é de mister que seja real, que prevaleça não-só de direito como de fato, que seja uma realidade e não-somente nominal, que seja efetiva e não uma idealidade apenas escrita. É essencial que seja respeitada, e fielmente observada, que cada poder efetivamente se contenha em sua órbita, que reciprocamente zelem de suas atribuições, não tolerando a invasão e o despojo de sua competência constitucional. Observar praticamente a sábia disposição do art. $9^{\circ}$ da lei fundamental é o grande desideratum, é a vida real do sistema constitucional. Quanto mais exata for essa observância, mais seguras e amplas serão as liberdades brasileiras, $e$ mais regular e bem ordenada a administração nacional, marcharemos então para prosperidade; haverá crenças, espírito nacional e entusiasmo."

Esse magistério notável, lúcido e extremamente atual, ministrado por um dos mais extraordinários constitucionalistas do Império, aluno da primeira turma, 
desta Faculdade de Direito, autoriza proclamar a asserção de que a construção da ordem democrática no Brasil ou em qualquer outro País, para ser plena, há de neutralizar os impulsos gerados no interior do próprio aparelho de Estado que incompreensivelmente estimulam a desconsideração do valor e do significado que uma ordem constitucional legítima deve representar para a consciência de homens livres e para as formações sociais organizadas de acordo com o princípio da liberdade.

Uma visão do processo político-institucional, que se recuse a compreender a supremacia da Constituição e que hesite em submeter-se à autoridade normativa de seus preceitos, notadamente daqueles que consubstanciam as cláusulas pétreas que protegem o núcleo irreformável e a essência mesma do pacto constitucional -, é censurável e é preocupante, pois torna evidente que ainda há, na intimidade do Poder, um resíduo de indisfarçável autoritarismo, despojado de qualquer coeficiente de legitimidade ético-jurídica.

Nesse contexto e com os olhos permanentemente voltados para recente período histórico, que, ao longo de 21 anos, aniquilou, em nosso País, o regime das franquias individuais e das conquistas políticas e sociais da cidadania, é preciso destacar a importância fundamental do Poder Judiciário na promoção da causa democrática e na defesa do princípio da liberdade.

Os magistrados devem obediência exclusiva à autoridade normativa que emerge da Constituição e que se funda no consenso dos governados. Os juízes têm e devem ter -, na ordem constitucional legitimamente estabelecida, o parâmetro inafastável de sua atuação institucional. Os órgãos do Poder Judiciário devem constituir o instrumento vital da cidadania na defesa do Estado democrático de Direito, pautando as suas ações pelo respeito incondicional aos postulados básicos, aos valores essenciais e aos objetivos fundamentais que conferem à Constituição do Brasil o sentido verdadeiramente democrático de que ela se acha impregnada.

A magistratura, que exerce a função jurisdicional por delegação soberana do Povo, não pode permitir, sob pena de grave infidelidade à alta missão institucional que the foi atribuída, que se organizem, no seio do Estado, sistemas marginais de poder, vocacionados a frustrar a força normativa da Constituição e a transformação, em prática banal e inconseqüente, o gesto inaceitável de descumprimento dos princípios constitucionais que estruturam, em nosso sistema jurídico, o modelo político de Estado democrático de Direito. 
O texto constitucional, por isso mesmo, não deve expor-se a manipulações exegéticas que somente visam a propiciar interpretações jurídicas destinadas a satisfazer a conveniência de determinados planos governamentais que se revelam incompatíveis com os postulados fundamentais da Carta Política. A Constituição não é mera lex privata. O governante não pode interpretá-la somente pro domo sua. Ela representa, na abrangência do seu subordinante domínio normativo, o instrumento de definição das relações institucionais entre os poderes da República, além de qualificar-se como o manto tutelar das liberdades públicas e de proteção social, política e jurídica da cidadania, em face da índole expansiva e muitas vezes arbitrária que caracteriza a atuação do poder estatal.

Interpretações facciosas da Constituição, que somente considerem, como perspectiva única do intérprete, a visão dos interesses próprios das agências governamentais, deslegitimam-se por si mesmas, em face da natureza de que se reveste o texto constitucional, vocacionado - enquanto obra de compromisso fundada no consenso emergente da comunhão nacional a tomar efetivos, na prática concreta das instituições, os postulados do pluralismo político, da livre circulação de idéias, das liberdades públicas e da divisão funcional do Poder.

O magistrado - para legitimar-se em sua função essencial de arbitrar os conflitos, dirimindo-os em caráter definitivo deve ser o intérprete fiel e o guardião escrupuloso dos princípios que dão à Constituição da República e ao ordenamento jurídico que com ela seja compatível - o sentido de instrumentos verdadeiramente democráticos, porque essencialmente fiéis à vontade que reflete os anseios supremos do Povo.

Recusar a supremacia da Constituição, para, sobre ela, fazer prevalecer a vontade pessoal do governante, significa romper a normalidade jurídica do Estado democrático de Direito.

Dentro desse específico contexto, cumpre registrar, com preocupação, que a experiência jurídica brasileira tem demonstrado, desde a vigência da nova Constituição, a ocorrência de uma crescente apropriação institucional, pela Presidência da República, do poder de legislar, que, por imposição dos postulados que regem o Estado democrático de Direito, pertence, exclusivamente, ao Congresso Nacional.

Essa progressiva ocupação, pelo Poder Executivo, do espaço constitucionalmente reservado à atuação da instituição parlamentar provoca graves distorções de caráter político-jurídico, pois as medidas provisórias considerada a 
essência democrática do regime constitucional que prevalece no Estado brasileiro não foram concebidas pela Assembléia Constituinte como instrumentos ordinários de substituição da atividade legislativa comum do Congresso Nacional.

É certo que as múltiplas exigências que concernem ao Estado contemporâneo impõem a adoção de mecanismos destinados a viabilizar uma produção normativa ágil e eficaz reclamáda por situações extraordinárias de necessidade e de urgência.

Essas situações extraordinárias de necessidade e de urgência muito embora legitimem, no contexto do modelo constitucional brasileiro, o exercício da atividade normativa primária pelo Executivo não conferem ao Presidente da República, a qualquer Presidente da República, o poder de manipular a excepcional competência de editar atos com força de lei, eis que essa prerrogativa de ordem institucional, por ñão se qualificar como um direito fora da Constituição, supõe, para efeito de seu válido exercício, a estrita observância das normas impostas pela própria Lei Fundamental.

Cumpre não-desconhecer, neste ponto, que é o Parlamento, no regime da separação de poderes, o único órgão estatal investido de legitimidade constitucional para elaborar, democraticamente, as leis do Estado.

Mais grave do que isso, no entanto, revela-se a conduta dos que, querendo impor a vontade do Estado, pretendem negar prepotentemente ao Judiciário, fundados em interpretações abstrusas e concepções equivocadas, a possibilidade de aplicar postulados da mais elevada estatura normativa, que encontram fundamento na própria Constituição da República. Esse gravíssimo comportamento governamental nada mais significa, na dimensão em que se projeta o nosso sistema de direito positivo, do que o deliberado e censurável intuito de praticar um ilícito constitucional, com grave subversão da hierarquia jurídica.

Somente pessoas desatentas ao fato de que vivemos sob um regime constitucional de poderes limitados, que se mostram infensas a qualquer compromisso com a ordem jurídica consagrada pela Constituição que representa, no seio das sociedades politicamente organizadas, o único parâmetro subordinante de todas as ações estatais seriam capazes de desrespeitar os fundamentos em que se assenta, em toda a extensão de sua legitimidade, o Estado democrático de Direito.

A missão política do Poder Judiciário reveste-se de um significado transcendental no plano de nossas instituições republicanas. 
A Constituição e as leis - todos o sabemos nada mais são do que a sua própria interpretação. No poder de interpretar o ordenamento jurídico reside a magna prerrogativa judicial de estabelecer o alcance e de definir o sentido da vontade normativa proclamada pelo Estado.

Eventual interpretação desfavorável das normas jurídicas não pode ser invocada como ato ofensivo ao princípio constitucional da legalidade e, muito menos, como gesto incompatível com o postulado da separação de poderes, especialmente quando se tem em conta a necessidade de fazer prevalecer, no processo de indagação do ordenamento normativo, postulados de irrecusável hierarquia, como o são aqueles que derivam da própria Constituição da República.

Os governantes não podem pretender que deles, unicamente deles, emanem as legítimas interpretações da Constituição e das leis. Esse não é o domínio institucional de sua atuação e nem essa constitui, no plano de nossa organização jurídica, a atividade preponderante que thes incumbe.

Interpretações regalistas da Constituição e das leis que visem a produzir exegeses servilmente ajustadas à visão e à conveniência exclusivas dos governantes e de estamentos dominantes no aparelho social representariam clara subversão da vontade inscrita no texto de nossa Lei Fundamental e ensejariam, a partir da temerária aceitação da soberania interpretativa manifestada pelos dirigentes do Estado, a deformação do sistema de discriminação de poderes fixado, de modo legítimo e incontrastável, pela Assembléia Nacional Constituinte.

Impõe-se relembrar e relembrar a todo momento que os poderes do Estado, em nosso sistema constitucional, são essencialmente definidos e precisamente limitados. "E a Constituição foi feita" adverte a doutrina (Hugo L. Black, "Crença na Constituição", p. 39, 1970, Forense) "para que esses limites não sejam mal interpretados ou esquecidos".

Tenho sempre enfatizado que uma Constituição escrita não configura mera peça jurídica subalterna, que possa sujeitar-se à vontade discricionária e irresponsável dos governantes, nem representa simples estrutura formal de normatividade e nem pode caracterizar ou ser interpretada como um irrelevante acidente histórico na vida dos povos e das Nações. A Constituição reflete um documento solene da maior importância político-jurídica, sob cujo império protegem-se as liberdades, impede-se a opressão governamental e repudia-se o abuso de poder. 
Ordens autoritárias, praticadas com abuso de poder e desrespeito ao texto constitucional, podem gerar e geram com certeza - a deliqüescência do regime democrático, desagregando-lhe as estruturas políticas, defraudando o seu sistema jurídico e descaracterizando-o naquilo que de mais essencial nele existe: o respeito incondicional e a submissão plena da autoridade pública ao império da Constituição.

Neste expressivo momento histórico de nossa experiência social, econômica e político-institucional, em que se processam fundadas discussões em torno dos limites que devem, necessariamente, condicionar a atividade jurídica do Estado (e do Poder Executivo em particular), torna-se imperioso reconhecer a importância da reflexão sobre o significado, para a vida das instituições e a prática das liberdades públicas, da supremacia da Constituição.

Sabemos que a necessidade de impor limitações jurídicas ao exercício do Poder estatal e a exigência de preservar, em benefício das pessoas e dos grupos sociais, o regime das liberdades públicas situam-se, historicamente, na gênese do processo de organização democrática e constitucional do Estado.

O constitucionalismo, por isso mesmo, enquanto processo e movimento, projetou-se numa dimensão político-jurídica e operou, em bases formais, a instauração de uma ordem normativa destinada a conter a própria onipotência do Estado.

O poder absoluto, exercido pelo Estado sem quaisquer restrições e controles, inviabiliza, numa comunidade estatal concreta, a prática efetiva das liberdades e o exercício dos direitos e garantias. Por isso mesmo, a sujeição do poder estatal a regras jurídicas claramente definidas e formalmente preestabelecidas no instrumento constitucional revela-se consequiência necessária da técnica de racionalização do poder, a qual visa, em última análise, por meio de sistemas institucionalizados de controle, a impedir, no processo governamental, o abuso de poder.

Não basta, pois, apresentar, o governante qualquer governante -, para justificar o exercício autorizado do poder, títulos de legitimidade que se apóiem nos valores em nome dos quais o próprio poder é exercido (José Eduardo Faria, "Poder e Legitimidade" p. 114, 1978, Editora Perspectiva).

Mais do que isso, é preciso respeitar, de modo incondicional, os parâmetros de atuação, delineados no texto constitucional, que impõem diretrizes e traçam esquemas normativos condicionadores da própria atuação governamental. 
Todos os atos estatais que repugnam à Constituição expõem-se à censura jurídica, dos Tribunais, especialmente - porque são írritos, nulos, desvestidos de qualquer validade.

O exercício das funções estatais sofre os rígidos condicionamentos impostos pela ordem constitucional. O extravasamento dos limites de sua atuação põe gravemente em causa a supremacia, formal e material, da Constituição e gera situações de conflituosidade jurídico-institucional, na medida em que os atos de usurpação qualificam-se como fatores de ruptura do equilíbrio entre $९$ s Poderes do Estado.

O constituinte brasileiro, ao elaborar a Constituição que nos rege, mostrou-se atento e sensível à experiência histórica de outros Povos e fez consagrar, na Carta Política que promulgou, fiel à nossa própria tradição constitucional, um princípio cuja essencialidade é marcante no plano das relações institucionais entre os órgãos da soberania nacional.

Esse princípio o da separação de poderes - a que é ínsito um sentido de fundamentalidade, foi proclamado, na Constituição brasileira de 1988, como um dos seus núcleos irreformáveis, insuscetível, até mesmo, de alteração por via de emenda constitucional (art. 60, $\S 4^{\circ}$. III).

E indubitável que nenhum dos poderes do Estado detém o monopólio de suas próprias atribuições (funções típicas). Cada qual exerce, em caráter secundário, atipicamente, atribuições jurídicas que, no plano constitucional, são preponderantemente deferidas, em razão de sua especialização funcional, aos demais poderes estatais.

O sistema de checks and balances, de freios e contrapesos, possibilita, pelo exercício de controles interorgânicos recíprocos, a harmonia e a interdependência entre os poderes do Estado, com o que se preserva o regime das liberdades públicas e se mantém, no plano da sociedade política, o equilibrio institucional entre esses mesmos poderes.

As recíprocas interferências dos poderes do Estado, uns nos outros, desde que ocorram nas hipóteses constitucionalmente autorizadas, não provocam a ruptura do sistema, porque por este expressamente previstas e disciplinadas.

Essa ruptura, no entanto, ocorrerá sempre que qualquer dos Poderes exercer, com expansão desordenada, atribuições que the não são próprias, ou, então, impedir, por atos que refogem à ortodoxia constitucional, o normal desempenho, 
pelos demais Poderes do Estado, de funções que lhes são inerentes, como a prática, em plenitude, do oficio jurisdicional por magistrados e Tribunais.

A Constituição não pode submeter-se ao império dos fatos e das circunstâncias. A supremacia de que ela se reveste, enquanto for respeitada, constituirá a garantia mais efetiva de que os direitos e as liberdades não serão jamais ofendidos.

A essencialidade das liberdades públicas, enquanto expressão concreta das conquistas individuais e sociais obtidas ao longo do desenvolvimento de nosso processo histórico e político, traduz o reconhecimento de que o poder do Estado não deve ser absoluto e de que a dignidade da pessoa humana, a importância da cidadania e a necessidade da prevalência do pluralismo político e do respeito ao postulado da separação de poderes constituem valores fundantes da própria ordem democrática.

É tempo de concluir.

Antes, contudo, torna-se necessário enfatizar que nenhum dos Poderes da República situa-se acima da Constituição.

A percepção dessa realidade, além de forjar em nossos espíritos a consciência da importância insuperável do estatuto constitucional fundado em bases democráticas, permite que não ignoremos, tanto governantes quanto governados, que o justo equilíbrio político entre os Poderes do Estado decorre do convívio harmonioso que deve necessariamente pautar as suas relações institucionais.

É preciso também acentuar que o Poder Judiciário, quando intervém para assegurar as franquias constitucionais, exerce, de maneira plenamente legítima, no âmbito concreto de uma comunidade verdadeiramente democrática, as atribuições que lhe conferiu a própria Carta da República.

Impõe-se reconhecer que o exercício regular da função jurisdicional, necessariamente pautado pelo respeito à Constituição, não-transgrido o princípio da separação de poderes. Antes, esse desempenho livre e independente da atividade jurisdicional revela o elevado índice de civilização de um Povo inspirado pela idéia essencial de respeito à ordem democrática.

Não constitui demasia insistir na asserção de que a submissão incondicional de todos ao império da Constituição representa o fator essencial de preservação, aperfeiçoamento e consolidação do regime democrático, por cuja integridade devemos velar, enquanto cidadãos e, também, enquanto legisladores, magistrados ou membros do Poder Executivo. 
Ao concluir o meu pronunciamento, desejo registrar, Senhor Diretor, a significativa importância da Faculdade de Direito do Largo de São Francisco no processo histórico e político-jurídico brasileiro.

Por tudo o que a velha e sempre nova Academia de São Paulo, que é a minha "alma mater", tem representado para o Brasil, significando, para todos nós, em todos os momentos da vida política nacional, o espaço essencial da defesa das liberdades e da luta pela construção e consolidação da ordem democrática, é que compareço a esta solenidade, como ex-aluno desta Casa, honrado em pronunciar-me como Presidente do Supremo Tribunal Federal, para estender a esta magnífica Instituição e a todos os seus eminentes Professores, Alunos e membros do corpo administrativo -, ao ensejo da celebração de seu $170^{\circ}$ aniversário de fundação, as saudações respeitosas da Suprema Corte do Brasil.

Muito obrigado.

São Paulo, 15 de agosto de 1997. 